\title{
Complete mtgenome sequences of Anopheles peditaeniatus and An. nitidus and phylogenetic relationships of the genus Anopheles based on mtgenome sequences (Diptera: Culicidae: Anophelinae)
}

Jing Guo

Chongqing Normal University

Zhen-Tian Yan

Chongqing Normal University

Wen-Bo Fu

Chongqing Normal University

Huan Yuan

Chongqing Normal University

Xu-Dong Li

Chongqing Normal University

Bin Chen ( $D$ c_bin@hotmail.com )

Chongqing Normal University https://orcid.org/0000-0002-5227-7736

\section{Research Article}

Keywords: mtgenomes, phylogenetics, Culicidae, Anopheles, Anopheles peditaeniatus, An. nitidus

Posted Date: May 10th, 2021

DOl: https://doi.org/10.21203/rs.3.rs-476684/v1

License: (c) (i) This work is licensed under a Creative Commons Attribution 4.0 International License.

Read Full License 


\section{Abstract}

Background: Despite the medical importance of the genus Anopheles in the transmission of malaria and other human diseases, its phylogenetic relationships are not unsettled and the characteristics of mitochondrial genome (mtgenome) are not well understood.

Methods: The present study sequenced and analyzed the complete mtgenomes of An. peditaeniatus and An. nitidus, and investigated the characteristics and phylogenetic relationships of 76 complete mtgenome sequences in the genus Anopheles using Illumina sequencing and bioinformatics techniques.

Results: The complete mtgenomes of An. peditaeniatus and An. nitidus are 15416 and 15418 bp long, respectively, and include 13 PCGs, 22 tRNAs, two tRNAs and one control region (CR). These 76 mtgenomes are similar as earlier reports in insects in general characteristics, and however the trnR and $\operatorname{trn} A$ have a reversal arrangement to form "trnR-trnA" as reported in other mosquito genera. Their variations mainly occur in CR with a length of 493 - $886 \mathrm{bp}$, and six repeat unit types are identified for the first time and demonstrate some evolutionary signals. The subgenera Lophopodomyia, Stethomyia, Kerteszia, Nyssorhynchus, Anopheles and Cellia, are proposed to be monophyletic with the phylogenetic relationships of (Lophopodomyia $+(($ Stethomyia + Kerteszia $)+($ Nyssorhynchus $+($ Anopheles + Cellia $))))$. Four series Neomyzomyia, Pyretophorous, Neocellia and Myzomyia in Cellia, and two series Arribalzagia and Myzorhynchus in Anopheles are proposed to be monophyletic, and three sections Myzorhynchella, Argyritarsis and Albimanus and their subdivisions in Nyssorhynchus all appear polyphyletic or paraphyletic.

Conclusions: The study comprehensively uncovered the characteristics of mtgenome and the phylogenetics based on mtgenomes in the genus Anopheles, and provided an information frame for further study on the mtgenomes, phylogenetics and taxonomic revision of the genus.

\section{Background}

The genus Anopheles belongs to the subfamily Anophelinae in Culicidae. It is the most diverse genus in the Subfamily, including 475 formally named species and more than 50 unnamed members of species complexes worldwide [1]. It can transmit a variety of diseases, and is thought to be the most important group of insects in medicine. Mosquitoes of the genus Anopheles are the unique vectors of human malarial parasites, which causes 228 million cases and 405,000 deaths worldwide in 2018 [2]. In addition to malaria parasites, mosquitoes in Anopheles also transmit filarial parasites [3]. Some studies have shown that Anopheles mosquitoes also harbor viruses, collectively termed the virome, and some of these viruses are arboviruses, which multiply in the mosquito vectors before transmission to a vertebrate host, such as o'nyong-nyong [4]. Other viruses may infect insect hosts but not infect vertebrates, and are called insect-specific viruses (ISV) [5]. Due to the exceeding importance, mosquitoes of the genus are subject to more taxonomic studies than any other mosquito genus. 
The classification of genus Anopheles started more than 100 years ago [6], in which it was treated as one of 18 genera in the Anophelinae, and Cellia, Nyssorhynchus, Stethomyia and Kerteszia were also treated as independent genera based on the morphological characteristics. Subsequently, the five genera were successively degraded as subgenera of the genus Anopheles based on the number and location of the specialized setae on male genital gonocoxites and other characteristics [7-9], and three additional subgenera, Lophopodomyia, Baimaia and Christya were established for the genus Anopheles [10-12]. Due to the diversity of species contained in subgenus Anopheles, Cellia and Nyssorhynchus, taxonomists divided some species into informal categories such as Sections, Series and Groups. Earliest phylogenetic studies for the genus Anopheles were mainly based on morphological characters and individual genes, different data sets and phylogenetic inference methods often lead inconsistent results, and therefore the phylogenetic relationship of Anopheles have not been well settled.

There have been a number of representative phylogenetic studies on the genus Anopheles. An analysis including 63 species in Anophelinae based on 163 morphological characters suggested the monophyly of the subgenera Cellia, Nyssorhynchus, StethomyiaKerteszia and Lophopodomyia. In Nysorhynchus, the three sections Albimanus, Argyritarsis and Myzorhynchella were suggested to be paraphyly; in Cellia, only series Cellia was considered to be monophyly; and in Anopheles, series Arribalzagia and Lophoscelomyia were considered to be monophyly, while series Cycloleppteron+Arribalzagia was nested in series series Myzorhynchus [13]. Some further morphology-based studies also suggested the monophyly of subgenera Nyssorhynchus, Cellia and Kerteszia, and displayed the sister relationships between subgenera Kerteszia and Nyssorhynchus [12, 14, 15]. An analysis based on COX1 + ITS2 dataset suggested the monophyly of the subgenus Anopheles (16 species included) and Cellia (18 species), and the analysis using ITS2 dataset alone resulted in the same conclusion but not for $\operatorname{COX} 1$ dataset alone [16]. Two studies based on the nucleotides of 13 protein-coding genes of mtgenomes, including 50 and 33 species, both also supported the monophyly of subgenera Anopheles, Nyssorhynchus, Cellia and Keterszia $[17,18]$. Generally, the monophyly of the subgenera Anopheles, Nyssorhynchus, Cellia, Stethomyia, Keterszia and Lophopodomyia have been suggested by most nowadays studies; however, the sections and series in the subgenera Anopheles, Nyssorhynchus and Cellia have not been well determined. There is a need to elucidate the phylogeny of the genus Anopheles using more species, more data and updated phylogenetic analysis approaches.

Mitochondria is a very important organelle in eukaryotic cells, which has a genome independent of the nuclear genome, namely "mitochondrial genome" (mtgenome) [19]. Mtgenome has the characteristics of small genome size, low level of recombination and maternal inheritance, and therefore it has been widely used as a molecular marker for identification of species, evolution, phylogenetic inference and population structure research $[20,21]$. Since the publication of the first insect mtgenome (Drosophila yakuba) in 1985 [22], the number of insect mtgenomes have increased rapidly. Phylogenetic studies based on insect mtgenomes have shown good results in Diptera [23], Orthoptera [24], Coleoptera [25] and Hymenoptera [26]. So far, NCBI has housed the complete mtgenomes of 125 species in Culicidae, of which 74 species belong to the genus Anopheles. The Diptera mtgenome is mostly 14-20 kb long, including 37 genes: 13 protein-coding genes (PCGs), 2 ribosomal RNA (rRNA) genes, 22 transfer RNA (tRNA) genes and a control 
region (CR), and these genes are arranged in a compact circular genome [27]. The gene number and structure in all reported mosquito mtgenomes are similar to the typical mtgenomes of Diptera, and however, $\operatorname{trn} A$ and $\operatorname{trn} R$ of mosquitoes are rearranged to form "trnR-trnA" arrangement $[17,18,22]$.

In the present study, we sequenced and annotated the complete mitogenomes of An. peditaeniatus and An. nitidus in the genus Anopheles, and comparatively analyzed the characteristics of 76 species of mtgenome sequences in the genus Anopheles. More importantly, we constructed and discussed the phylogenetic relationships of these 76 known mtgenome sequences. The study provided new insight of the mtgenomes characteristics and phylogenetic relationships in the genus Anopheles.

\section{Methods}

\section{Sample collection and DNA extraction}

Specimens of An. peditaeniatus and An. nitidus were collected from Yadong County $\left(29^{\circ} 11^{\prime} 46^{\prime \prime} \mathrm{N}\right.$, $\left.95^{\circ} 12^{\prime} 11^{\prime \prime} \mathrm{E}\right)$, Tibet, China in July 2014 , and Tiebei County, Jilin Province, China (42 $\left.27^{\prime} 21^{\prime \prime} \mathrm{N}, 128^{\circ} 06^{\prime} 18^{\prime \prime} \mathrm{E}\right)$ in July 2013, respectively. All collected samples were preserved in individual vials in silica. After morphological identification in laboratory [28], these samples were stored in $100 \%$ alcohol, and housed at $-20^{\circ} \mathrm{C}$ until the DNA extraction. Total DNA was extracted from the individual adult mosquito using the Qiagen Genomic DNA Kit [29], and used for 350 bp library construction and Illumina high throughout sequencing of mitochondrial genome in Shenzhen Huitong Biotechnology Co. Ltd..

\section{Mtgenomes assembly, annotation and characteristics analysis}

The mtgenomes of An. peditaeniatus and An. nitidus assemblied and annotated using Mitos (http://mitos.bioinf.unileipzig.de/index.py) [30]. The annotation of 13 PCGs and two rRNA genes wase confirmed in reference of known mosquito mtgenomes, and corrected using Geneious v4.8.5 [31]. The secondary structures of tRNAs were predicted using tRNAscan-SE 2.0 [32], and the structure map of the mtgenomes were visualized using OGDRAW1.3.1 [33]. The base composition, codon usage, relative synonymous codon usage (RSCU), and amino acid content were computed with MEGA v.7.0.26 software [34]. The nucleotide composition bias was calculated using the formulas AT skew $=[A-T] /[A+T]$ and GC skew $=[G-C] /[G+C][35]$, and the Three-dimensional scatterplot of the AT-Skew, GC-Skew and AT\% was drawn using Origin Pro v.9.0 [36]. The selection pressure of 13 PCGs during the evolution process was analyzed by calculating $\mathrm{Ka}$ and $\mathrm{Ks}$ values using DnaSP v6.12.03. Sequence motifs in the CR were identified using the Tandem Repeats Finder program [37].

\section{Phylogenetic analysis}

Multiple sequence alignment of 13 PCGs was performed on the Translator-X Server (http://translatorx.co.uk/), in which MAFFT was used to align the amino acid sequences of 13 PCGs, and Gblocks was used to remove poorly aligned sites. Finally, the individual alignments were connected 
together using SequenceMatrix [38] to obtain the amino acid tandem sequence of 13 PCGs. The best-fit substitution model for nucleotide datasets was selected by PartitionFinder 2 [39].

Phylogenetic analyses of the 76 Anopheles species of mtgenomes (two sequenced in the study and 74 known) were performed using the Maximum likelihood (ML) analysis in IQ-TREE 1.6.10 [40], and the Bayesian Inference (BI) analysis in MrBayes v.3.2.7a [41] using Culex pipiens pallens as the outgroup (Table 1). The bootstrap values were calculated with 1000 replicates for $\mathrm{ML}$, and for $\mathrm{BI}$, performed two independent runs, each with four chains, and these chains ran simultaneously for 1,000,000 generations, and the tree being sampling every 1000 steps with $25 \%$ burn-in rate. The phylogenetic tree was drawn using FigTreev.1.4.4 (http://tree.bio.ed.ac.uk/software/figtree/).

\section{Results}

\section{Nucleotide composition and genome organization}

The complete mtgenomes of An. peditaeniatus (MT822295) and An. nitidus (MW401801) are both circular, closed and double-stranded structures, with full lengths of 15,416 and $15,418 \mathrm{bp}$, respectively (Fig. 1). Both are composed of 37 genes (including 13 PCGs, 22 tRNA genes and two rRNA genes) and one control region (CR). There are 22 genes (nine PCGs and 13 tRNAs) located on the majority coding strand (J-strand), while the other 15 genes (four PCGs, nine tRNAs and two rRNAs) are on the minority strand (N-strand). Compared with the typical Diptera mtgenome (Drosophila yakuba), both An.

peditaeniatus and An. nitidus have "trnR-trnA" rearrangements. The AT content of the mtgenomes of the two species are as high as $78.32 \%$ and $78.26 \%$, respectively, which are significantly higher than their GC content $(21.68 \%, 21.74 \%)$, showing obvious AT bias (Additional file 1: Table S1). The AT-skew of An. peditaeniatus (0.0322) is higher than the average AT-skew of all investigated mosquito mtgenomes (0.0283), whereas the AT-skew of An. nitidus mtgenome (0.0266) is lower than the average AT-skew value. The GC-skew in An. peditaeniatus(-0.1587) and An. nitidus (-0.1536) are higher than the average GC-skew value in mosquitoes investigated $(-0.16048)$.

The three-dimensional scatter plot of the AT content, AT-skew and GC-skew of 76 mtgenomes in the genus Anopheles is shown in Fig. 2. The AT-skew with the range of variation from 0.005 for An. gilesi to 0.043 for An. christyi. However, all mtgenomes display negative GC-skews ranging from -0.207 for $A n$. parvus to -0.136 for An. punctulatus. Most of the species of the subgenera Nyssorhynchus and Cellia have similar AT content and AT/GC-skew, which are closely distributed in the Three-dimensional scatter plot, whereas the species of the subgenera Lophopodomyia, Stethomyia, Kerteszia and Anopheles are widely distributed in the plot for AT content, AT-skew and GC-skew.

\section{Protein-coding genes}

The total nucleotide lengths of the 13 PCGs of An. peditaeniatus and An. nitidus is 11,223 and 11,168 bp, respectively. In the An. peditaeniatus, ATN is used as the start codon, except for COX1 and ND5 which use 
TCG and GTG as the start codon, respectively, and in the An. nitidus, 13 PCGs initiate with ATN as the start codon, but COX1 uses TCG as a start codon (Table 2).

The RSCU values of 76 species of mtgenomes in the genus Anopheles are presented in Additional file 2: Table S2. The mtgenomes of the Anopheles have relatively different usage frequencies of synonymous codons. In the 76 species, UUA is the most frequently used codon, followed by CGA, GGA, GCU. The amino acid Leu has the highest usage percentage for all $76 \mathrm{mtgenomes}$ investigated with an average of $16.37 \%$, followed by Phe (9.69\%), lle (9.31\%) and Ser (8.48\%), whereas Cys has the lowest percentage $(0.99 \%)$. The usage percentages of amino acids seem no obvious difference among different subgenera (Fig. 3).

The non-synonymous (Ka) and synonymous (Ks) substitution ratio (Ka/Ks) of 13 PCGs are shown in the Fig. 4. The $\mathrm{Ka} / \mathrm{Ks}$ ratios are all less than 1 , and the $N D 6$ has the highest $\mathrm{Ka} / \mathrm{Ks}$ ratio $(0.203)$, followed by six genes (ATP8, ND2, ND5, ND4L, ND4, ND3) with Ka/Ks ratios of 0.098-0.152. Complex IV (COX1, COX2 and COX3), Complex III (CYTB), ND1 and ATP6 have low Ka/Ks ratios with range from 0.022 (COX1) to 0.051 (ND1). These results imply all of these 13 PCPs experienced purifying selection, especially Complex IV, Complex III, ND1 and ATP6.

\section{Transfer RNAs, ribosomal RNAs and CR}

The total length of 22 tRNAs of An. peditaeniatus and An. nitidus is $1475 \mathrm{bp}$ and $1476 \mathrm{bp}$, respectively, and the length of these 22 tRNAs varies from 64 to $72 \mathrm{bp}$. All tRNAs can fold into the typical clover-leaf structure, containing four stems and loops except for trnS2 which lost the dihydrouridine (DHU) arm. There are 22 mismatched base pairs(G-U) to be found in An. peditaeniatus tRNAs, and 21 mismatched base pairs(G-U) in An. nitidus (Additional file 3: Figure S1). In the two newly sequenced mtgenomes, $r r n L$ is located between $t r n L 2$ and $t r n V$, and $r r n S$ between $t r n V$ and CR. The length of the rRNAs is $2125 \mathrm{bp}$, with an AT content of $81.36 \%$ in An. punctulatus, 2122 bp, with an AT content of $81.39 \% \%$ in An. nitidus.

The control regions (CRs) of the mtgenomes are both located between $r r n S$ and $t r n /$ with their lengths of 575 and $580 \mathrm{bp}$, and their AT content of $94.43 \%$ and $93.62 \%$ (the highest among all mtgenome regions), respectively in An. peditaeniatus and An. nitidus. Six repeat unit types are identified in the CRs of the 74 species of mtgenomes in Anopheles (Additional fle 4: Fig S2). All species have the repeat unit type of 15$27 \mathrm{bp}$ poly-T Stretch, which is located in front of other repeat unit types and just after 140-212 bp of conserved sequence. The poly-T Stretch is adjacently connected with the conserved motif 5'-CCCCTA-3' in the conserved sequence in 68 species, whereas the motif was substituted by 5'-ATTGTA-3' in An. cracens and An. dirus, and 5'-TTCCCC-3' in An. kompi, An. nimbus, An. gilesi and An. pseudotibiamaculatus. The second type is a 12-55 bp sequence with 2-6 repeats, which is just after the poly-T Stretch and exists in 54 species. The third type ([TA(A)]n Stretch) contains 22-91 repeats, which exists in 36 species. The fourth type is a 12-38 bp sequence with 2-5 repeats which are near $t r n /$ and exist in 40 species. The remaining two repeat unit types are found in only a few species, one of them is a 15-36 bp sequence which after the second type and exists in 5 species; and the last one is a 108-171 bp sequence, which is longest one among all six types and only exists in four species. 


\section{Phylogenetic relationships}

Bayesian inference $(\mathrm{BI})$ and Maximum-likelihood $(\mathrm{ML})$ analyses produced two same topology of phylogenetic trees in the subgenus-level (Fig. 5-6). The six subgenera investigated, Lophopodomyia, Stethomyia, Kerteszia, Nyssorhynchus, Anopheles and Cellia all seem to be monophyly in both analyses, with posterior probability (pp) $=1$ for every subgenus in $\mathrm{BI}$ (Fig 5 ) and bootstrap values (bv) ranging from $99 \%$ to $100 \%$ in ML analysis (Fig. 6). The subgenus Lophopodomyia is located at the base of these six subgenera, and the branch comprising the remaining five subgenera has the support of $\mathrm{pp}=1$ and $\mathrm{bv}=$ $71 \%$. The two subgenera Stethomyia and Kerteszia form a monophyly with $\mathrm{pp}=1$ and bv $=89 \%$, which was earliest derived but the Lophopodomyia. The branch containing the Nyssorhynchus, Anopheles and Cellia possess the support of $\mathrm{pp}=1$ and bv $=68 \%$. The subgenus the Nyssorhynchus seems to be sister group with the monophyly Anopheles + Cellia that has $\mathrm{pp}=1$ and $\mathrm{bv}=99 \%$.

In the subgenus Cellis, four series investigated, Myzomyia, Neocellia, Pyretophorus and Neomyzomyia each seem monophyletic with $\mathrm{pp}=1$ and $\mathrm{bv}=100 \%$ for all of these monophylies. The series Neomyzomyia would be earliest derived and sister with remaining three seriers, and the series Pyretophorus would be sister with series Myzomyia and Neocellia. In the subgenus Anopheles, two sections Angusticorn and Laticorn both seem polyphyletic, and in section Laticorn both series Arribalzagia ( $\mathrm{pp}=1$ and $\mathrm{bv}=96 \%$ ) and Myzorhynchus ( $\mathrm{pp}=1$ and $\mathrm{bv}=100 \%$ ) seem monophyletic. In the subgenus Nyssorhynchus, three sections investigated Myzorhynchella, Argyritarsis and Albimanus all seem polyphyletic, and in the section Argyritarsis, two series Argyritarsis and Albitarsis both seem polyphyletic as well.

On the other hand, internal relationships of the Kerteszia are different of $\mathrm{BI}$ tree and Ml tree: $A n$. homunculus branched out earlier than An. bellator in BI-tree (Fig. 5), however, in ML-tree, An. bellator branched out earlier than An. homunculus (Fig. 6).

\section{Discussion}

\section{Characteristics of the mtgenome sequences of the genus Anopheles}

The length of 76 mtgenomes in the genus Anopheles ranges from 15,573 bp to 15,803 bp, and the length variation mainly occurred in the $\mathrm{CRs}$, which is similar as earlier reported mtgenomes in insects [42, 43]. Each mtgenome sequence includes 37 genes, and the $\operatorname{trn} R$ and $\operatorname{trn} A$ have a reversal arrangement to form "trnR-trnA" in comparison of Drosophila yakuba, as those reported in other genera in Culicidae [22,45]. All tRNA genes can form a complete clover secondary structure, except for trnS2 that lacks the DHU arm, which seem to be a common feature of metazoans [43]. The nucleotide composition for all species exhibits high AT bias with AT-skew values all positive and GC-skew all negative, similar as earlier reports in insects. The 13 PCGs mainly use ATN as the start codon and TAA as the stop codon, which is similar as other mtgenome sequences in insects [43]. The usage frequencies of synonymous codons and amino acids vary with the codon UAA having the highest usage frequency, followed by CGA and GGA, and the amino acid Leu to be most used, followed Phe and Ile. This is the detailed analysis for the usage 
frequency for the first time, and may potentially contribute the biochemical and functional characteristics of mitochondrial genes.

The lengths of CRs are quite variable with range from $493 \mathrm{bp}$ to $886 \mathrm{bp}$. The present study identified six repeat unit types for the first time. All mtgenome sequences investigated have the poly-T stretch, which may involve in the identification of the replication origin of mtDNA [44]. The remaining five repeat unit types vary in length and position among species, some of them seem different among subgenera to some extent. For example, the third type ([TA(A)]n Stretch) were not found in subgenera Anopheles, Lophopodomyia and Stethomyia, and the longest type only found in subgenera Lophopodomyia and Kerteszia. The CRs have been reported to be taxon-specific and of evolutionary information, and was used as an important evidence in the inference of phylogenetics in genus Culex and Lutzia and taxon [46]. However, the evolutionary information carried in the genus Anopheles does not seem stable and reliable.

\section{Phylogenetics relationships}

This present study suggests that these six subgenera investigated are all monophyletic, and the phylogenetic relationships among subgenera are Lophopodomyia + ((Stethomyia + Kerteszia) + $($ Nyssorhynchus $+($ Anopheles + Cellia $))))$.

A phylogeny study based on 163 morphological characters for 64 species in the subfamily Anophelinae with Approximations Weighting (AW) method in 2000 showed that the subgenera Lophopodomyia, Stethomyia, Kerteszia, Nyssorhynchus and Cellia were monophyletic, whereas the subgenus Anopheles polyphyletic. These two subgenera Lophopodomyia and Stethomyia were separately linked inside the subgenus Anopheles [13]. A further morphology-based phylogenetics analysis published in 2005 used 167 characters for 66 species in the Anophelinae with both Equal Weighting (EW) and Implied Weighting (IW) methods, which got the same results as described above [15]. All analyses from these three methods showed that the two subgenera Nyssorhynchus and Kerteszia were sister-group, and the AW and EW methods suggested a relationship (Nyssorhynchus + Kerteszia $)+($ Cellia + (Lophopodomyia + Stethomyia + Anopheles) $)$, whereas the IW method suggested (Anopheles + Lophopodomyia + Stethomyia $)+($ Cellia + (Kerteszia + Nyssorhynchus)). For molecular-based phylogenetic analysis, a study using COI, COIl and 5.8S rRNA for 47 species in the genus Anopheles with ML method in 2015 suggested the monophyly of the subgenus Stethomyia, Kerteszia, Nyssorhynchus, Anopheles and Cellia with the phylogenetic relationships Anopheles +(Cellia + (Nyssorhynchus + (Stethomyia + Kerteszia)) $)$ [48]. A study using a.a. sequences of 1,085 single-copy orthologous genes for 18 species of the subgenera Nyssorhynchus, Anopheles and Cellia with ML method in 2015 proposed that all of these three subgenera are monophyletic with the relationships (Nyssorhynchus + (Anopheles + Cellia)) relationship [49]. Our earlier study using all PCG nucleotide sequences of 50 mtgenomes in Culicidae with ML and BI method in 2017 showed that the subgenera Nyssorhynchus, Anopheles and Cellia are monophyletic with the relationships (Nyssorhynchus $+($ Anopheles + Cellia) $)[17]$. 
All these six subgenera included in these comprehensive phylogenetic analyses above were suggested to be monophyly except for the subgenus Anopheles, which was recognized as a polyphyly in two morphology-based inferences while as a monophyly in three molecular-based inferences. Importantly, the study based on 18 whole nuclear genomes showed that the subgenus Anopheles is monophyletic [49]. This present study supported the monophyly of these six subgenera, resulting from these molecularbased inferences. The studies based on 18 whole nuclear genomes [50] and 50 whole mtgenomes [17] suggested that the subgenus Nyssorhynchus be sister group with (Anopheles + Cellia), and the study supports the result. The study based on $\mathrm{COI}$, COIl and 5.8S rRNA suggested the sister relationship of the subgenera Stethomyia and Kerteszia [48], and the study supports the result. The subgenus Lophopodomyia were grouped with the subgenera Anopheles and Stethomyia in two morphology-based inferences [13,15], whereas it was not included in the molecular-based inferences $[17,48,49]$. This study suggests that the subgenus Lophopodomyia be the sister with other five subgenera together. In general, the phylogenetic relationships constructed between morphology-based and molecular-based inference are quite different, and there is need of further studies with inclusion of more species and data to elucidate the among-subgenera relationships.

For the subgenus Cellia, four series Neomyzomyia, Pyretophorous, Neocellia and Myzomyia investigated all appear to be monophyletic ( $\mathrm{pp}=1$ and $\mathrm{bv}=100 \%$ for their clades), with the phylogenetic relationships of Neomyzomyia + (Pyretophorous + (Neocellia + Myzomyia)). The results are completely consistent with those of our earlier study that was also based on whole mtgenomes [17], and almost consistent with the phylogenetic study based on 18S, 28S, COI and COII data in monophyly and relationship [47]. However, the early morphology-based study in 2000 treated the four series as paraphyly [13]. These suggest that results stemmed from molecular and morphology are often conflicting as discussed above.

For the subgenus Anopheles, the two sections Angusticorn (only series Anopheles included) and Laticorn (two series Myzorhynchus and Arribalzagia included) both seem to be polyphyletic. The two series Myzorhynchus and Arribalzagia would be monopheletic ( $\mathrm{pp}=1$ and bv ${ }^{3} 96 \%$ for their clades), and if $A n$. lindesayi were excluded, the series Anopheles would also be monopheletic ( $\mathrm{pp}=0.92$ and bv $=85 \%$ ), with the relations of (Anopheles + (Myzorhynchus + Arribalzagia)). The phylogenetic study based on COI, COII and 5.8S rRNA suggested the sections Laticorn and Angusticorn be polyphyletic, and inside the two series Anopheles and Myzorhynchus involved also be polyphyletic. In two morphology-based studies, one based on 163 morphological characters proposed the sections Laticorn and Angusticorn to be polyphyletic, the series Arribalzagia to be monophyletic, and the two series Myzorhynchus and Anopheles to be paraphyletic [13]. The another based on 167 morphological characters proposed the section Laticorn to be monophyletic, the section Angusticorn to be polyphyletic, the two series Arribalzagia and Myzorhynchus to be monphyletic, and the series Anopheles to be polyphyletic [15]. All of these four studies suggested that the section Angusticorn be polyphyletic, in which the series Anopheles be polyphyletic, and most of these studies proposed that the section Laticorn be polyphyletic, in which the series Arribalzagia be monophyletic and the series Myzorhynchus may be monophyletic. 
For the subgenus Nyssorhynchus, three sections Myzorhynchella, Argyritarsis and Albimanus investigated, and their subdivisions in the three sections all appear polyphyletic or paraphyletic. The morphology-based study based on 163 morphological characters data suggested the three sections Albimanus, Argyritarsis and Myzorhynchella were paraphyletic [13]. In two molecular-based study, one based on white and ND6 for 21 species in the Nyssorhynchus with BI method in 2010 [50] suggested the three sections be not monophyletic, and a another one based on white, $C A D$ and $C O /$ for 32 species in Nyssorhynchus with BI method in 2013 showed the three sections to be polyphyletic, and the three series also to polyphyletic [51]. All of these four studies demonstrate that the taxonomy and phylogenetics of the subgenus are quite conflicted, and there is more necessarity to reconstruct the taxonomic system of the subgenus along the phylogenetic study.

\section{Conclusions}

This study sequenced and analyzed the complete mtgenomes of An. peditaeniatus and An. nitidus, and investigated the characteristics and phylogenetic relationships of 76 complete mtgenome sequences in the genus Anopheles. These mtgenomes are of general characteristics similar as earlier reports in insects, and however the $\operatorname{trn} R$ and $\operatorname{trn} A$ have a reversal arrangement to form "trnR-trnA" in comparison of Drosophilayakuba mtgenomes as those reported in other genera in Culicidae. Their variations mainly occur in CR regions with length from 493 bp - 886 bp, and six repeat unit types are identified for the first time, which demonstrate the evolutionary importance among subgenera to some extent. The subgenera Lophopodomyia, Stethomyia, Kerteszia, Nyssorhynchus, Anopheles and Cellia are all proposed to be monophyletic with the phylogenetic relationships of Lophopodomyia + ((Stethomyia + Kerteszia $)+$ $($ Nyssorhynchus $+($ Anopheles + Cellia $))))$. Four series Neomyzomyia, Pyretophorous, Neocellia and Myzomyia in the subgenus Cellia, are proposed to be monophyletic, two series Arribalzagia and Myzorhynchus in the subgenus Anopheles are proposed to be monophyletic while the series Anopheles seems polyphyletic, and three sections Myzorhynchella, Argyritarsis and Albimanus and their subdivisions in the subgenus Nyssorhynchus all appear polyphyletic or paraphyletic. In general, there is need of further studies with inclusion of more species and data to elucidate the phylogenetic relationships in the genus.

\section{Declarations}

\section{Ethics approval and consent to participate}

Not applicable.

\section{Consent for publication}

Not applicable.

\section{Availability of data and materials}


All data are available as tables and figures in the main document and its additional files. The GenBank accession numbers for the two mtgenomes produced in the present study are MW401801 and MT822295.

\section{Competing interests}

The authors declare that they have no competing interests.

\section{Funding}

This research was supported by the following, The National Natural Science Foundation of China (31872262, 31672363), National Key Program of Science and Technology Foundation Work of China (2015FY210300).

\section{Authors' contributions}

$\mathrm{BC}$ and $\mathrm{JG}$ conceived and designed the study. JG and $\mathrm{BC}$ performed the experiments and data analysis, and drafted the manuscript. ZTY, WBF, HY and XDL joined the specimens collecting and experiments. All authors read and approved the final version of the manuscript.

\section{Acknowledgements}

This research was supported by the following, The National Natural Science Foundation of China (31872262, 31672363), National Key Program of Science and Technology Foundation Work of China (2015FY210300).

\section{Authors' information}

Chongqing Key Laboratory of Vector Insects; Institute of Entomology and Molecular Biology, College of Life Sciences, Chongqing Normal University, Chongqing 401331, P. R. China.

\section{Abbreviations}

mtgenome: mitochondrial genome; PCGs: protein-coding genes; rRNAs: ribosomal RNA genes; tRNAs: transfer RNA genes; CR: control region; RSCU: relative synonymous codon usage; BI: Bayesian inference; ML: Maximum likelihood.

\section{References}

1. Harbach RE. An Anopheles by Any Other Name ...?. J Med Entomol. 2018;5:1-2.

2. World Health Organization. World Malaria Report 2019; World Health Organization: Geneva, Switzerland, 2019. 
3. Derua YA, Alifrangis M, Magesa SM, Kisinza WN, Simonsen PE. Sibling species of the Anopheles funestus group, and their infection with malaria and lymphatic filarial parasites, in archived and newly collected specimens from northeastern Tanzania. Malaria Journal. 2015;14:104-112.

4. Sim C, Hong YS, Vanlandingham DL, Harker BW, Christophides FC, et al. Modulation of Anopheles gambiae gene expression in response to o'nyong-nyong virus infection[J]. Insect Molecular Biology. 2010;14(5):475-481.

5. Bolling BG, Weaver SC, Tesh RB, Vasilakis N. Insect-specifc virus discovery: significance for the Arbovirus Community. Viruses. 2015;7(9):4911-

6. Theobald FV. The classification of the Anophelina[J]. J TROP MEDUS. 1902;5:181-183.

7. Christophers SR. The Male Genitalia of Anopheles. Indian J Med Sci. 1915;3:371-394.

8. Edwards FW. Genera Insectorum. Diptera, Fam.Culicidae. Fascicle 194 Bruxelles, Belgium: Desmet Verteneuil; 1932.

9. Komp WHW. The Species of the Subgenus Kerteszia of Anopheles (Diptera, Culicidae). Ann Entomol Soc Am.1937;30:492-529.

10. Antunes, PCA. A new Anopheles and a new Goeldia from Colombia (Dipt. Culic.). Bull Entomol Res. 1937;28:69-73.

11. Harbach RE, Rattanarithikul R, Harrision BA. Baimaia, a new subgenus for Anopheles kyondawensis Abraham, a unique crabhole-breeding anopheline in Southeastern Asia. P Eentomol Soc Washp. 2005;107:750-761.

12. Harbach RE, Kitching IJ. The phylogeny of Anophelinae revisited: inferences about the origin and classification of Anopheles (Diptera: Culicidae). Zool Scr. 2015;45:34-47.

13. Sallum MAM, Schultz TR, Wilkerson RC. Phylogeny of Anophelinae (Diptera Culicidae) based on morphological characters. Ann Entomol Soc Am. 2000;93:745-775.

14. Collucci E, Sallum MAM. Phylogenetic analysis of the subgenus Kerteszia of Anopheles (Diptera: Culicidae: Anophelinae) based on morphological characters. Insect Syst Evol. 2003;34:361-372.

15. Harbach RE, Kitching IJ. Reconsideration of Anopheline mosquito phylogeny (Diptera: Culicidae: Anophelinae) based on morphological data. Syst Biodivers. 2005;3:345-374.

16. Fateh K, Ali OM, Mahdi SM, Waterhouse RM, Hasan V, Ali HBA, et al. Phylogenetic Analysis of the Oriental Palearctic Afrotropical Members of Anopheles (Culicidae: Diptera) Based on Nuclear rDNA and Mitochondrial DNA Characteristics. Jpn J Infect Dis. 2014;67:361-367.

17. Hao YJ, Zou YL, Ding YR, Xu WY, Yan ZT, Li XD, et al. Complete mitochondrial genomes of Anopheles stephensi and Anopheles dirus and comparative evolutionary mitochondriomics of 50 mosquitoes. Sci Rep. 2017;7:7666.

18. Mao QM, LI TJ, Fu WB, YAN ZT, Chen B. Sequencing of the complete mitochondrial genome of Anopheles lindesayi and a phylogenetic analysis of the genus Anopheles ( Diptera: Culicidae) based on mitochondrial genomes. Acta Entomol Sinica. 2019;62:103-118.

19. Boore Jl. Animal mitochondrial genomes. Nucleic acids research. 1999;27:1767-1780. 
20. Shao R, Barker SC. Mitochondrial genomes of parasitic arthropods: implications for studies of population genetics and evolution. Parasitology. 2007;134:153-167.

21. Cameron SL. Insect mitochondrial genomics: implications for evolution and phylogeny. Annu Rev Entomol. 2013;59:95-117.

22. Clary DO, Wolstenholme DR. The mitochondrial DNA molecular of Drosophila yakuba: nucleotide sequence, gene organization, and genetic code. J Mol Evol. 1985;22:252-71.

23. Cameron SL, Lambkin CL, Barker SC, Whiting MF: A mitochondrial genome phylogeny of Diptera: whole genome sequence data accurately resolve relationships over broad timescales with high precision. Syst Eetomol. 2007;32:40-59.

24. Chang HH, Qiu ZY, Yuan H, Wang XY, Li XJ, Sun HM, et al. Evolutionary rates of and selective constraints on the mitochondrial genomes of Orthoptera insects with different wing types. Mol Phylogenet Evol.2020;145:106734.

25. Yuan ML, Zhang QL, Zhang L, Guo ZL, Liu YJ, Shen YY, et al. High-level phylogeny of the Coleoptera inferred with mitochondrial genome sequences. Mol Phylogenet Evol. 2016;104:99-111.

26. Tang P, Zhu JC, Zheng BY, Wei SJ, Sharkey M, Chen XX, et al. Mitochondrial phylogenomics of the Hymenoptera. Mol Phylogenet Evol. 2018;131:8-18.

27. Zhang NX, Yu G, Li TJ, He QY, Zhou Y, Si FL, et al. The complete mitochondrial genome of Delia antiqua and its implications in dipteran phylogenetics. PLoS ONE. 2015;10:e0139736.

28. Lu BL. Fauna Sinica. Insecta. Diptera: Culicidae 1. Vol. 8. Beijing, China:Science Press;1997.

29. Yang FL, Li XD, Yan ZT, Chen B. The molecular identification markers of Anopheles sinensis. Chongqing Normal Univ (Nat Sci). 2014;31:40-44.

30. Bernt M, Donath A, Juhling F, Externbrink F, Florentz C, Fritzsch G, et al. MITOS: improved de novo metazoan mitochondrial genome annotation. Mol. Phylogenet. Evol.. 2013;69:313-319.

31. Kearse M, Moir R, Wilson A, Stones-Havas S, Cheung M, Sturrock S, et al. Geneious basic: an integrated and extendable desktop software platform for the organization and analysis of sequence data. Bioinformatics. 2012;28:1647-1649.

32. Lowe TM, Eddy SR. tRNAscan-SE: a program for improved detection of transfer RNA genes in genomic sequence. Nucleic Acids Res. 1997;25:955-964.

33. Lohse M, Drechsel O, Bock R. Organellar Genome DRAW (OGDRAW): a tool for the easy generation of high-quality custom graphical maps of plastid and mitochondrial genomes. Curr Genet. 2007;52:267-274.

34. Tamura K, Stecher G, Peterson D, Filipski A, Kumar S. MEGA6: Molecular Evolutionary Genetics Analysis Version 6.0. Mol Biol Evol. 2013;30:2725-2729.

35. Perna NT, Kocher TD. Patterns of nucleotide composition at four-fold degenerate sites of animal mitogenomes. J Mol Evol. 1995;41:353-358.

36. Mikrajuddin A, Khairurrijal A. A simple method for determining surface porosity based on SEM images using Origin Pro software. Indonesian J Phys. 2009;20:37-41. 
37. Benson G. Tandem repeats fnder: a program to analyze DNA sequences. Nucleic Acids Res. 1999;27:573-580.

38. Vaidya G, Lohman DJ, Meier R. SequenceMatrix: concatenation software for the fast assembly of multi-gene datasets with character set and codon information. Cladistics. 2011;27:171-180.

39. Lanfear R, Frandsen PB, Wright AM, Senfeld T, Calcott B. PartitionFinder 2: new methods for selecting partitioned models of evolution for molecular and morphological phylogenetic analyses. Mol Biol Evol. 2017;34:772-773.

40. Nguyen L, Schmidt H, Haeseler A, Minh B, IQ-TREE: a fast and effective stochastic algorithm for estimating maximum-likelihood phylogenies, Mol Biol Evol. 2015;32:268-274.

41. Ronquist F, Teslenko M, Mark P, Ayres D, Darling A, Hohna S, Larget B, Liu L, Suchard M, Huelsenbeck J, MrBayes 3.2: efficient Bayesian phylogenetic in- ference and model choice across a large model space. Syst Biol. 2015;61:539-542.

42. Beard CB, Hamm D, Collins FH. The mitogenome of the mosquito Anopheles gambiae: DNA sequence, genome organization, and comparisons with mitochondrial sequences of other insects. Insect Mol Biol. 1993;2:103-124.

43. Wolstenholme DR. Animal mitochondrial DNA: structure and evolution. Int Rev Cytol. 1992;141:173216.

44. Saito, S. Replication origin of mitochondrial DNA in insects. Genetics. 2005; 171:1695-1705.

45. Behura SK, Lobo NF, Haas B, Debruyn B, Lovin DD, Shumway MF, et al. Complete sequences of mitochondria genomes of Aedes aegypti and Culex quinquefasciatus and comparative analysis of mitochondrial DNA fragments inserted in the nuclear genomes. Insect Biochem Mol. 2011;41:770777.

46. Sun L, Li TJ, Fu WB, Yan ZT, Si FL, Zhang YJ, et al. The complete mt genomes of Lutzia halifaxia, fuscanus and Culex pallidothorax (Diptera: Culicidae) and comparative analysis of 16 Culex and Lutzia mt genome sequences[J]. Parasite Vector. 2019;12:368-381.

47. Sallum MAM, Schultz TR, Foster PG, Aronstein K, Wirtz RA, Wilkerson RC. Phylogeny of Anophelinae (Diptera:Culicidae) based on nuclear ribosomal and mitochondrial DNA sequences. Syst Entomol. 2002;27:361-382.

48. Freitas LA, Russo CAM, Voloch CM, Mutaquiha OCF, Marques LP, Schrago CG, et al. Diversification of the Genus Anopheles and a Neotropical Clade from the Late Cretaceous. PLoS ONE. 2015;10:e0134462.

49. Neafsey DE, Waterhouse RM, Abai MR, Aganezov SS, Alekseyev MA, Allen JE, et al. Mosquito genomics. Highly evolvable malaria vectors: the genomes of 16 Anopheles Science. 2015;347(6217):1258522.

50. Bourke BP , Foster PG , Bergo ES, Calado DC, Sallum MAM. Phylogenetic relationships among species of Anopheles (Nyssorhynchus) (Diptera, Culicidae) based on nuclear and mitochondrial gene sequences.[J]. Acta tropica. 2010;114(2):88-96. 
51. Foster P G , Bergo E S , Bourke B P, et al. Phylogenetic Analysis and DNA-based Species Confirmation in Anopheles (Nyssorhynchus)[J]. PLoS ONE. 2013;8(2):e54063.

\section{Tables}

Table 1 Detailed sequence information of mtgenomes used in the present phylogenetic analysis. 


\begin{tabular}{|c|c|c|c|c|c|c|c|}
\hline Sections/Series & Species & $\begin{array}{l}\text { Total } \\
\text { size } \\
(\mathrm{bp}) \\
\end{array}$ & $\begin{array}{l}\text { PCGs } \\
\text { size } \\
\text { (bp) } \\
\end{array}$ & $\begin{array}{l}\text { tRNA } \\
\text { size } \\
\text { (bp) } \\
\end{array}$ & $\begin{array}{l}\text { rRNA } \\
\text { size } \\
\text { (bp) } \\
\end{array}$ & $\begin{array}{l}\text { CR } \\
\text { size (bp) }\end{array}$ & $\begin{array}{l}\text { GenBank } \\
\text { ID }\end{array}$ \\
\hline \multicolumn{8}{|l|}{ Subgenus Cellia } \\
\hline \multirow[t]{5}{*}{ /Myzomyia } & An. aconitus & 15359 & 11224 & 1472 & 2114 & 519 & NC039540 \\
\hline & An. culicifacies & 15364 & 11194 & 1474 & 2121 & 535 & NC028216 \\
\hline & An. culicifacies B & 15330 & 11230 & 1474 & 2114 & 498 & NC027502 \\
\hline & An. funestus & 15356 & 11231 & 1477 & 2121 & 519 & NC038158 \\
\hline & An. minimus & 15411 & 11194 & 1476 & 2117 & 546 & NC028221 \\
\hline \multirow[t]{3}{*}{ /Neocellia } & An. maculatus & 14850 & 11188 & 1479 & 2108 & $\mathrm{~N} / \mathrm{A}$ & NC028218 \\
\hline & An. splendidus & 15362 & 11224 & 1477 & 2121 & 510 & NC039397 \\
\hline & An. stephensi & 15387 & 11190 & 1477 & 2117 & 551 & NC028223 \\
\hline \multirow[t]{5}{*}{ /Neomyzomyia } & An. cracens & 15412 & 11224 & 1482 & 2123 & 576 & NC020768 \\
\hline & An. dirus & 15406 & 11224 & 1478 & 2124 & 568 & NC036263 \\
\hline & An. farauti 4 & 15412 & 11224 & 1482 & 2125 & 576 & NC020770 \\
\hline & An. hinesorum & 15336 & 11224 & 1479 & 2123 & 505 & NC020769 \\
\hline & An. punctulatus & 15322 & 11187 & 1477 & 2118 & 493 & NC028222 \\
\hline \multirow[t]{7}{*}{ /Pyretophorus } & An. arabiensis & 15369 & 11194 & 1477 & 2122 & 530 & NC028212 \\
\hline & An. christyi & 14967 & 11188 & 1477 & 2126 & $\mathrm{~N} / \mathrm{A}$ & NC028214 \\
\hline & An. coluzzii & 15441 & 11194 & 1478 & 2124 & 599 & NC028215 \\
\hline & An. epiroticus & 15379 & 11188 & 1479 & 2122 & 535 & NC028217 \\
\hline & An. gambiae & 15363 & 11230 & 1479 & 2125 & 519 & NC002084 \\
\hline & An. melas & 15366 & 11194 & 1477 & 2122 & 526 & NC028219 \\
\hline & An. merus & 15365 & 11188 & 1478 & 2121 & 525 & NC028220 \\
\hline \multicolumn{8}{|l|}{ Subgenus Anopheles } \\
\hline \multirow[t]{4}{*}{ Angusticorn/Anopheles } & An. atroparvus & 15458 & 11175 & 1474 & 2161 & 614 & NC028213 \\
\hline & An. eiseni geometricus & 15696 & 11241 & 1474 & 2120 & 860 & MF381678 \\
\hline & An. lindesayi & 15366 & 11225 & 1475 & 2123 & 531 & KX961140 \\
\hline & An. quadrimaculatus A & 15455 & 11220 & 1473 & 2115 & 625 & NC000875 \\
\hline \multirow[t]{7}{*}{ Laticorn/Arribalzagia } & An. costai & 15433 & 11241 & 1473 & 2122 & 598 & NC037794 \\
\hline & An. nr. costai & 15434 & 11241 & 1473 & 2121 & 600 & NC037821 \\
\hline & An. fluminensis & 15429 & 11241 & 1474 & 2120 & 594 & NC037818 \\
\hline & An. forattinii & 15459 & 11241 & 1473 & 2125 & 615 & NC037813 \\
\hline & An. medialis ${ }^{*}$ & 15409 & 11241 & 1475 & 2121 & 545 & NC037789 \\
\hline & An. minor & 15466 & 11238 & 1478 & 2123 & 594 & NC037802 \\
\hline & An. peryassui & 15417 & 11241 & 1474 & 2120 & 585 & NC037790 \\
\hline Laticorn/Myzorhynchus & An. coustani & 15408 & 11194 & 1475 & 2112 & 570 & MT806097 \\
\hline An. nitidus & 15418 & 11168 & 1476 & 2122 & 580 & MW401801 & \\
\hline \multirow[t]{2}{*}{ An. peditaeniatus } & 15416 & 11224 & 1477 & 2125 & 575 & MT822295 & \\
\hline & An. sinensis & 15418 & 11224 & 1473 & 2125 & 577 & MF322628 \\
\hline
\end{tabular}

Subgenus Nyssorhynchus 


\begin{tabular}{|c|c|c|c|c|c|c|c|}
\hline \multirow[t]{14}{*}{ Albimanus/Oswaldoi } & An. albertoi & 15385 & 11240 & 1475 & 2114 & 558 & NC037804 \\
\hline & An. arthuri & 15387 & 11240 & 1475 & 2114 & 560 & NC037806 \\
\hline & An. benarrochi & 15387 & 11240 & 1477 & 2116 & 556 & NC037787 \\
\hline & An. evansae & 15382 & 11240 & 1477 & 2115 & 553 & NC037795 \\
\hline & An. galvaoi & 15420 & 11240 & 1477 & 2150 & 555 & NC037814 \\
\hline & An. goeldii & 15391 & 11240 & 1477 & 2117 & 560 & NC037810 \\
\hline & An. konderi & 15395 & 11240 & 1478 & 2125 & 555 & MF381685 \\
\hline & An. nuneztovari & 15393 & 11240 & 1477 & 2117 & 562 & MF381680 \\
\hline & An. oswaldoi & 15380 & 11237 & 1477 & 2115 & 554 & NC037793 \\
\hline & An. rangeli & 15386 & 11240 & 1477 & 2114 & 558 & NC037786 \\
\hline & An. rondoni & 15385 & 11240 & 1477 & 2113 & 557 & NC037815 \\
\hline & An. striatus & 15385 & 11240 & 1476 & 2115 & 557 & NC037801 \\
\hline & An. strodei & 15388 & 11240 & 1475 & 2115 & 560 & NC037808 \\
\hline & An. triannulatus & 15401 & 11240 & 1477 & 2125 & 559 & NC037800 \\
\hline \multirow[t]{9}{*}{ Argyritarsis/Albitarsis } & An. albitarsis & 15413 & 11216 & 1477 & 2119 & 575 & NC020662 \\
\hline & An. albitarsis F & 15418 & 11216 & 1479 & 2121 & 578 & NC030768 \\
\hline & An. albitarsis G & 15474 & 11216 & 1480 & 2125 & 615 & NC030766 \\
\hline & An. braziliensis & 15397 & 11240 & 1480 & 2115 & 562 & NC037791 \\
\hline & An. nr. braziliensis & 15413 & 11240 & 1478 & 2116 & 578 & MF381606 \\
\hline & An. deaneorum & 15424 & 11216 & 1476 & 2121 & 581 & NC020663 \\
\hline & An. janconnae & 15425 & 11216 & 1480 & 2120 & 575 & NC030767 \\
\hline & An. marajoara & 15453 & 11240 & 1476 & 2132 & 584 & NC037788 \\
\hline & An. oryzalimnetes & 15422 & 11216 & 1479 & 2120 & 581 & NC030765 \\
\hline \multirow[t]{5}{*}{ Argyritarsis/Argyritarsis } & An. argyritarsis & 15403 & 11240 & 1481 & 2115 & 579 & $\mathrm{NC} 037807$ \\
\hline & An. atacamensis & 15412 & 11241 & 1476 & 2122 & 564 & NC037792 \\
\hline & An. darlingi & 15386 & 11240 & 1489 & 2122 & 554 & NC014275 \\
\hline & An. lanei & 15396 & 11240 & 1478 & 2116 & 567 & NC037799 \\
\hline & An. sawyeri & 15417 & 11240 & 1477 & 2116 & 599 & NC037798 \\
\hline \multirow[t]{5}{*}{ Myzorhynchella/ } & An. antunesi & 15427 & 11242 & 1475 & 2118 & 595 & NC037817 \\
\hline & An. guarani & 15531 & 11241 & 1473 & 2119 & 700 & NC037816 \\
\hline & An. lutzii & 15341 & 11242 & 1475 & 2118 & 509 & NC037820 \\
\hline & An. parvus & 15444 & 11235 & 1470 & 2116 & 617 & NC037805 \\
\hline & An. pristinus & 15405 & 11241 & 1476 & 2117 & 581 & $\mathrm{NC} 037824$ \\
\hline \multicolumn{8}{|l|}{ Subgenus Kerteszia } \\
\hline & An. bellator & 15668 & 11242 & 1477 & 2126 & 811 & NC030249 \\
\hline & An. cruzii & 15449 & 11230 & 1478 & 2116 & 600 & $\mathrm{NC} 024740$ \\
\hline & An. homunculus & 15739 & 11242 & 1475 & 2125 & 886 & NC030248 \\
\hline & An. laneanus & 15446 & 11242 & 1479 & 2124 & 591 & NC030250 \\
\hline
\end{tabular}

Subgenus Stethomyia An. kompi 
Subgenus Lophopodomyia

An. gilesi

An.

pseudotibiamaculatus

$15458 \quad 11244 \quad 1465$

15597

11242

1478

2108

648

NC037803

NC037829

Outgroup

${ }^{*}$ Anopheles medialis $($ Harbach, 2018) = Anopheles intermedius (Peryassú, 1908).

Table 2 Organization of the An. peditaeniatus and An. nitidus mtgenomes. 


\begin{tabular}{|c|c|c|c|c|c|c|c|c|}
\hline \multirow[t]{2}{*}{ Gene } & \multirow[t]{2}{*}{ Strand } & \multicolumn{2}{|c|}{ Position (bp) } & \multicolumn{2}{|c|}{ Length (bp) } & \multicolumn{2}{|c|}{ Space(+)/overlap(-) } & \multirow{2}{*}{$\frac{\text { Start/Stop codon }}{\text { punctulaturitidus }}$} \\
\hline & & punctulatus & nitidus & punctulatus & nitidus & punctulatus & nitidus & \\
\hline $\operatorname{trn} I$ & $\mathrm{~J}$ & $1-68$ & $1-68$ & 68 & 68 & 0 & 0 & \\
\hline $\operatorname{trn} Q$ & $\mathrm{~N}$ & $66-134$ & $66-134$ & 69 & 69 & -3 & -3 & \\
\hline $\operatorname{trn} M$ & $\mathrm{~J}$ & $1134-202$ & $134-202$ & 69 & 69 & -1 & -1 & \\
\hline nad2 & $\mathrm{J}$ & $203-1228$ & $203-1228$ & 1026 & 1026 & 0 & 0 & ATT/TAA ATT/TAA \\
\hline $\operatorname{trn} W$ & $\mathrm{~J}$ & $1227-1295$ & $1227-1295$ & 69 & 69 & -2 & -2 & \\
\hline $\operatorname{trn} C$ & $\mathrm{~N}$ & $1295-1358$ & $1295-1358$ & 64 & 64 & -1 & -1 & \\
\hline $\operatorname{trn} Y$ & $\mathrm{~N}$ & $1360-1425$ & $1360-1425$ & 66 & 66 & 1 & 1 & \\
\hline $\operatorname{cox} 1$ & $\mathrm{~J}$ & $1424-2960$ & $1424-2965$ & 1537 & 1542 & -2 & -2 & TCG/TAA \\
\hline $\operatorname{trn} L 1$ & $\mathrm{~J}$ & $2961-3026$ & $2961-3026$ & 66 & 66 & 0 & -5 & \\
\hline $\operatorname{cox} 2$ & $\mathrm{~J}$ & $3028-3712$ & $3028-3712$ & 685 & 685 & 1 & 1 & ATG/T \\
\hline $\operatorname{trn} K$ & $\mathrm{~J}$ & $3713-3784$ & $3713-3784$ & 72 & 72 & 0 & 0 & \\
\hline $\operatorname{trn} D$ & $\mathrm{~J}$ & $3797-3865$ & $3797-3865$ & 69 & 69 & 12 & 12 & \\
\hline atp8 & $\mathrm{J}$ & $3866-4027$ & $3866-4027$ & 162 & 162 & 0 & 0 & ATT/TAA ATT/TAA \\
\hline atp6 & $\mathrm{J}$ & $4021-4701$ & $4021-4701$ & 681 & 681 & -7 & -7 & ATG/TAA ATG/TAA \\
\hline $\operatorname{cox} 3$ & $\mathrm{~J}$ & $4701-5487$ & $4701-5495$ & 787 & 795 & -1 & -1 & ATG/TAA \\
\hline $\operatorname{trn} G$ & $\mathrm{~J}$ & $5488-5554$ & $5488-5554$ & 67 & 67 & 0 & -8 & \\
\hline nad3 & $\mathrm{J}$ & $5555-5908$ & $5555-5908$ & 354 & 354 & 0 & 0 & ATA/TAA ATA/TAA \\
\hline $\operatorname{trn} R$ & $\mathrm{~J}$ & $5907-5970$ & $5907-5970$ & 64 & 64 & -2 & -2 & \\
\hline $\operatorname{trn} A$ & $\mathrm{~J}$ & $5974-6038$ & $5971-6036$ & 65 & 66 & 3 & 0 & \\
\hline $\operatorname{trn} N$ & $\mathrm{~J}$ & 6039-6105 & $6037-6103$ & 67 & 67 & 0 & 0 & \\
\hline $\operatorname{trn} S 2$ & $\mathrm{~N}$ & $6106-6172$ & 6104-6170 & 67 & 67 & 0 & 0 & \\
\hline $\operatorname{trn} E$ & $\mathrm{~J}$ & $6174-6239$ & $6172-6237$ & 66 & 66 & 1 & 1 & \\
\hline $\operatorname{trn} F$ & $\mathrm{~N}$ & $6238-6304$ & $6236-6302$ & 67 & 67 & -2 & -2 & \\
\hline nad5 & $\mathrm{N}$ & $6304-8046$ & $6302-8017$ & 1743 & 1766 & -1 & -1 & GTG/TAA ATT/TAA \\
\hline $\operatorname{trn} H$ & $\mathrm{~N}$ & $8047-8110$ & 8045-8109 & 64 & 65 & 0 & 27 & \\
\hline nad4 & $\mathrm{N}$ & $8111-9452$ & $8113-9451$ & 1342 & 1339 & 0 & 3 & ATG $/ \mathrm{T} \quad$ ATG $/ \mathrm{T}$ \\
\hline $\operatorname{nad} 4 L$ & $\mathrm{~N}$ & $9446-9745$ & $9445-9744$ & 300 & 300 & -7 & -7 & ATG/TAA ATG/TAA \\
\hline $\operatorname{trn} T$ & $\mathrm{~J}$ & $9752-9816$ & $9751-9815$ & 65 & 65 & 6 & 6 & \\
\hline $\operatorname{trn} P$ & $\mathrm{~N}$ & 9817-9882 & $9816-9881$ & 66 & 66 & 0 & 0 & \\
\hline nad6 & $\mathrm{J}$ & 9885-10409 & 9884-10408 & 525 & 525 & 2 & 2 & ATT/TAA ATT/TAA \\
\hline$c o b$ & $\mathrm{~J}$ & $10409-11545$ & $10408-11544$ & 1137 & 1137 & -1 & -1 & ATG/TAA ATG/TAA \\
\hline $\operatorname{trnS1}$ & $\mathrm{J}$ & 11544-11609 & $11543-11608$ & 66 & 66 & -2 & -2 & \\
\hline nad1 & $\mathrm{N}$ & $11628-12572$ & $11629-12573$ & 945 & 945 & 18 & 20 & ATT/TAA ATT/TAA \\
\hline $\operatorname{trn} L 2$ & $\mathrm{~N}$ & $12579-12644$ & $12580-12645$ & 66 & 66 & 6 & 6 & \\
\hline $\operatorname{rrnL}$ & $\mathrm{N}$ & $12645-13972$ & $12646-13973$ & 1328 & 1328 & 0 & 0 & \\
\hline $\operatorname{trn} V$ & $\mathrm{~N}$ & $13973-14044$ & $13974-14044$ & 72 & 72 & 0 & 0 & \\
\hline $\operatorname{rrn} S$ & $\mathrm{~N}$ & $14045-14841$ & $14045-14838$ & 797 & 794 & 0 & 0 & \\
\hline CR & & $14842-15416$ & $14839-15418$ & 575 & 579 & 0 & 0 & \\
\hline
\end{tabular}


Figures
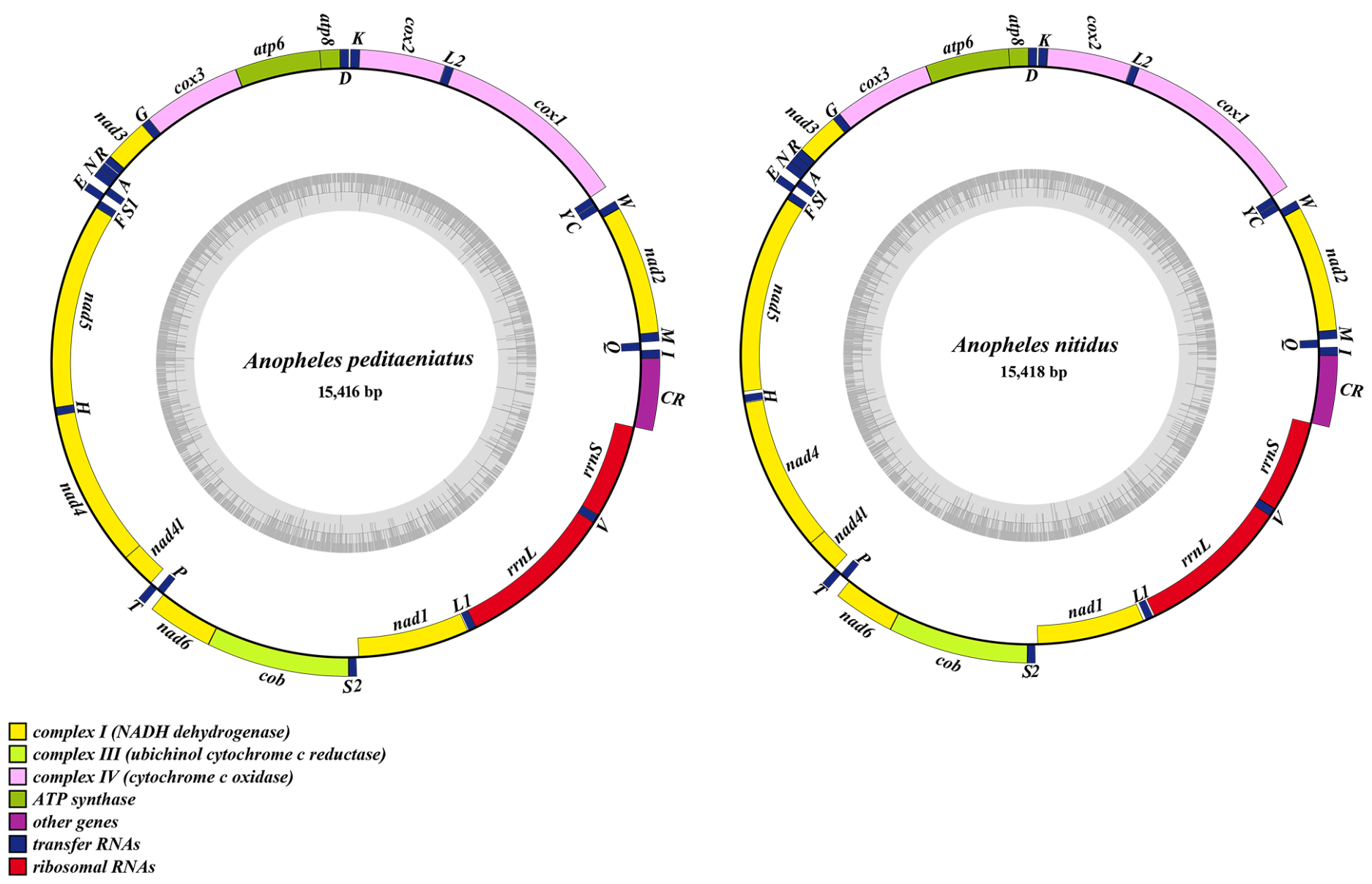

Figure 1

Mtgenome structure of An. peditaeniatus and An. nitidus. 


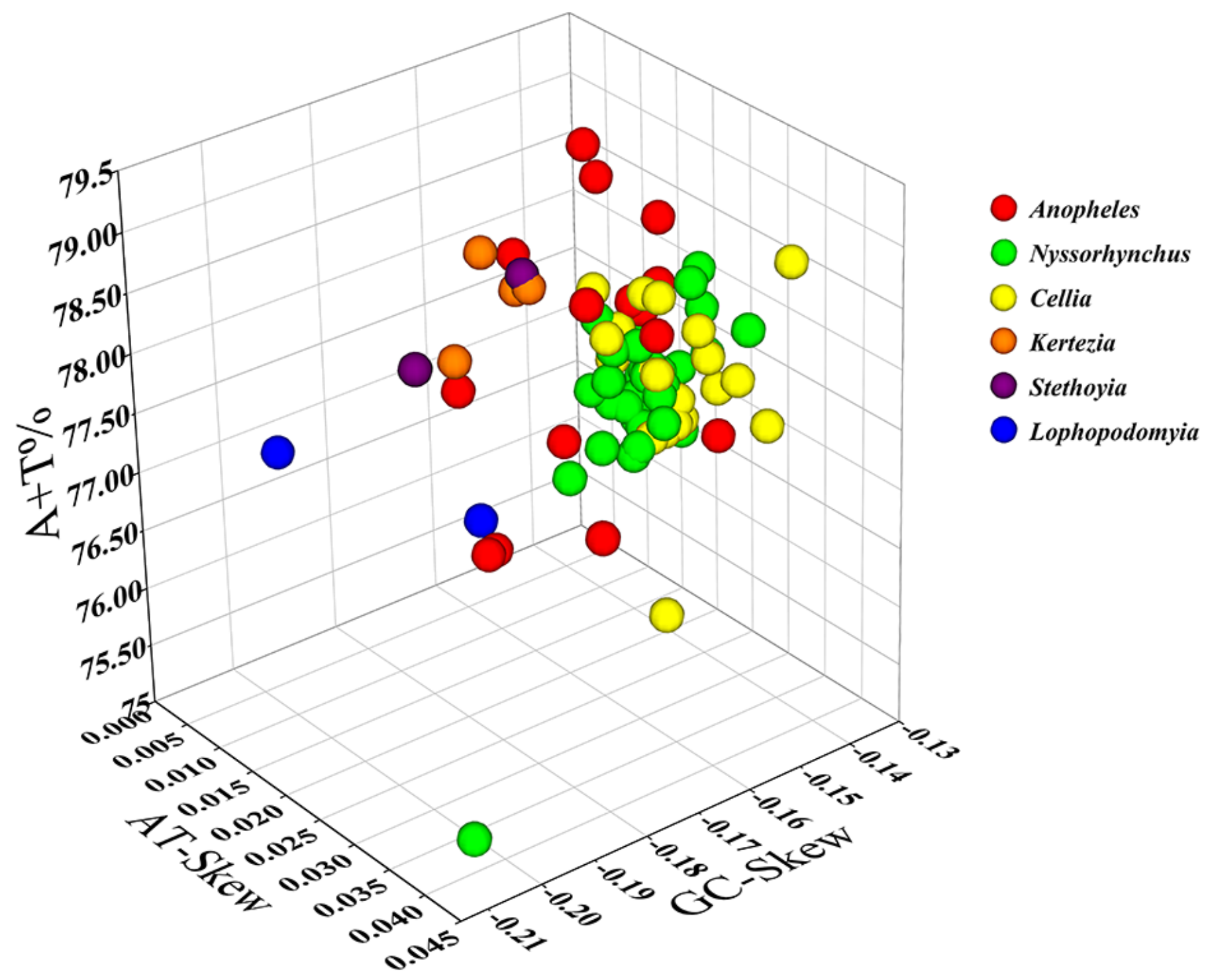

Figure 2

Three-dimensional scatter plot of the AT-Skew, GC-Skew and AT\% of $76 \mathrm{mtgenome} \mathrm{sequences} \mathrm{in} \mathrm{the}$ genus Anopheles. 


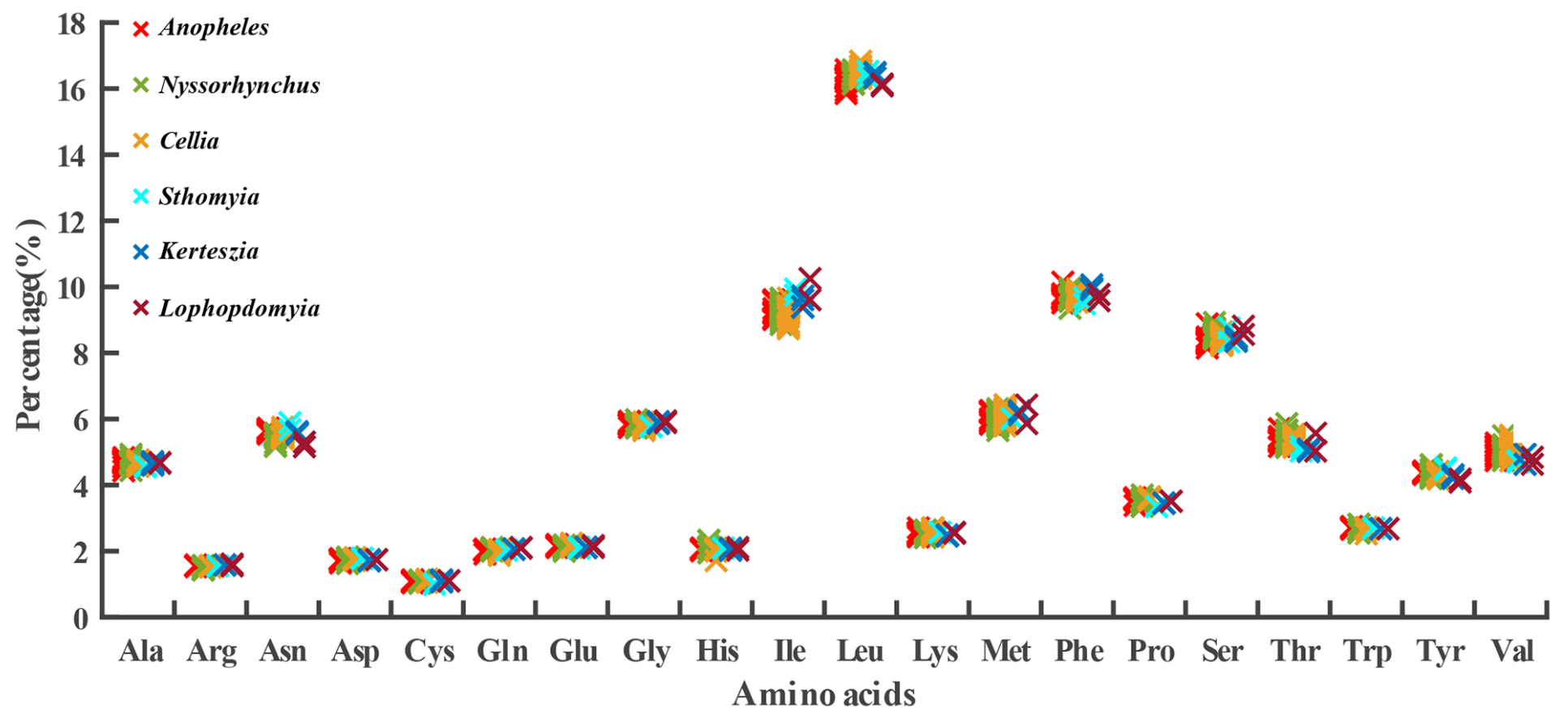

Figure 3

Frequency percentage of each of 20 coded amino acids in 76 mtgenome sequences in the genus Anopheles. 


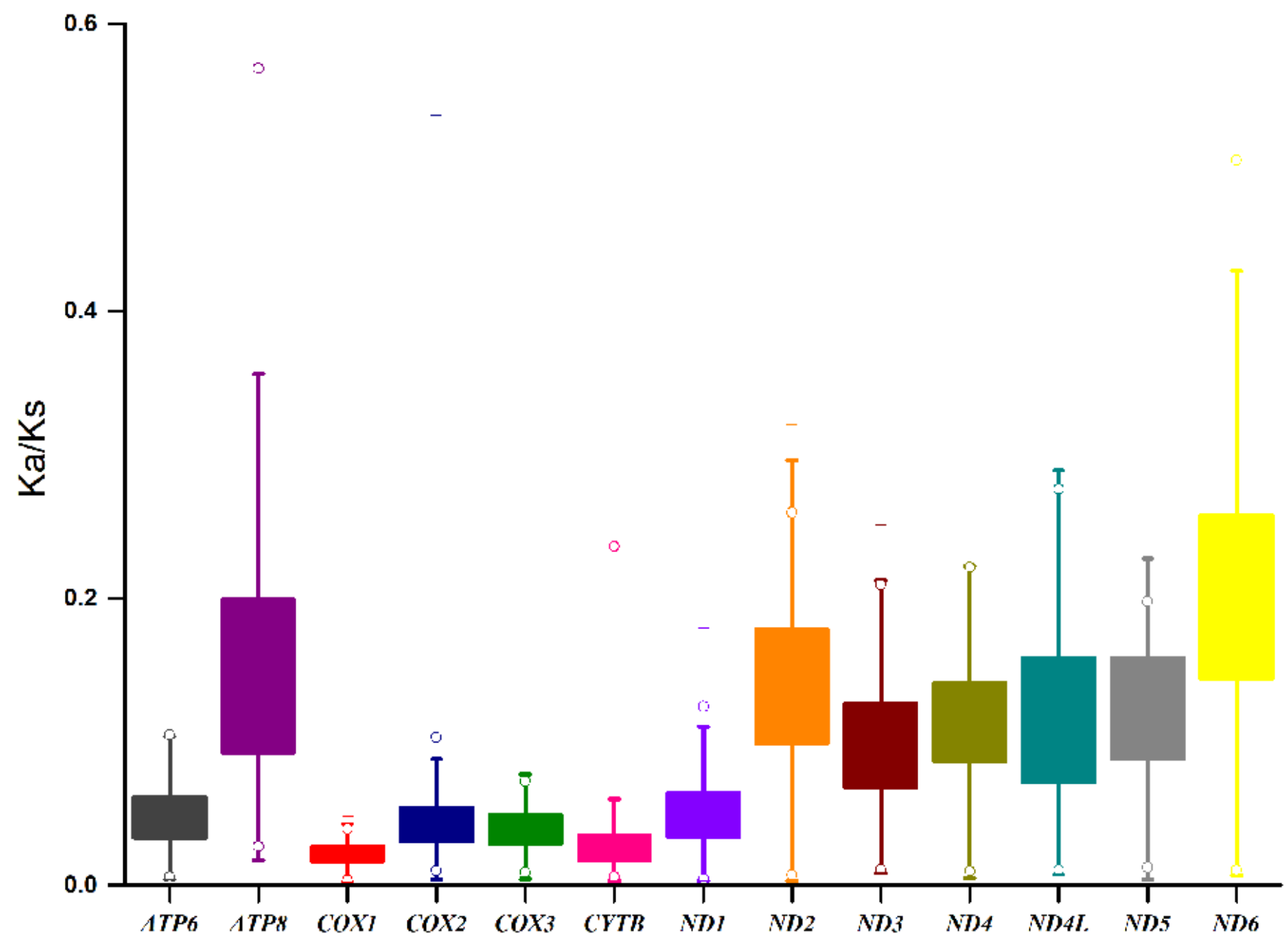

Figure 4

Evolutionary rates of 13 protein-coding genes (PCGs) within 76 mtgenomes in the genus Anopheles. Ka: Non-synonymous mutation rate; Ks: Synonymous mutation rate; Ka/Ks: The ratio of non-synonymous mutation rate to synonymous mutation rate. Neutral evolution $(K a / K s=1)$, Purify selection $(K a / K s<1)$, Positive selection $(\mathrm{Ka} / \mathrm{Ks}>1)$. 


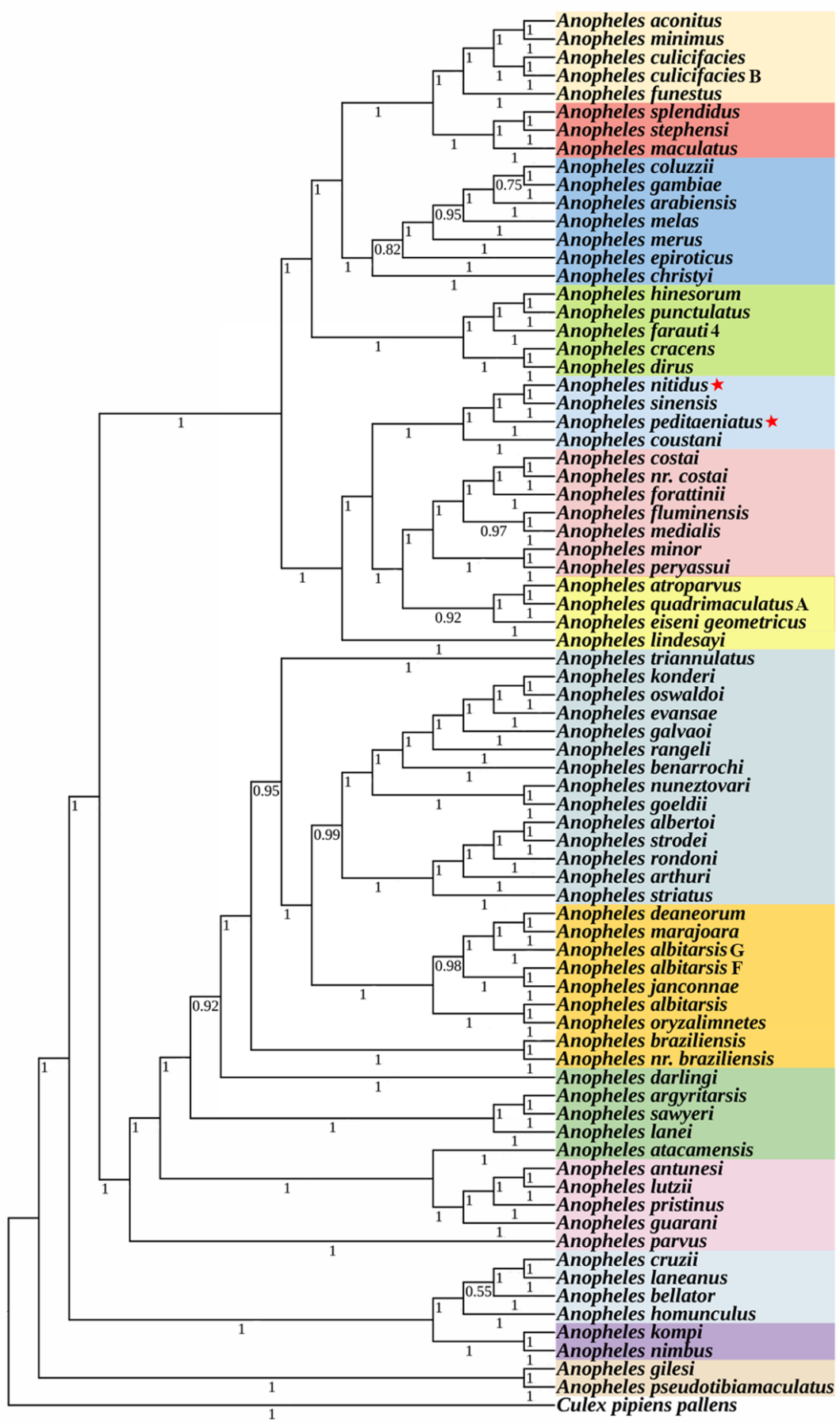

Myzomyia

Neocellia

Pyretophorous

\section{Cellia}

Neomyzomyia

Myzorhynchu
Arribalzagia
Anopheles

Laticorn

Anopheles

Oswaldoi

Albimanus

Albitarsis

Argyritarsis

Outgroup

Myzorhynchella

Kerteszia

Stethomyia

Lophopodomyia

\section{Figure 5}

Phylogenetic relationships of $76 \mathrm{mtgenomes}$ in the genus Anopheles. The phylogenetic tree was constructed based on nucleotide sequences of 13 protein-coding genes using MrBayes Infereence. The numbers at the nodes is Bayesian posterior probabilities. The mtgenomes of two species newly sequenced in this study are indicated by pentagrams. The GenBank accession numbers of the 76 mtgenome sequences are listed in Table 1. 


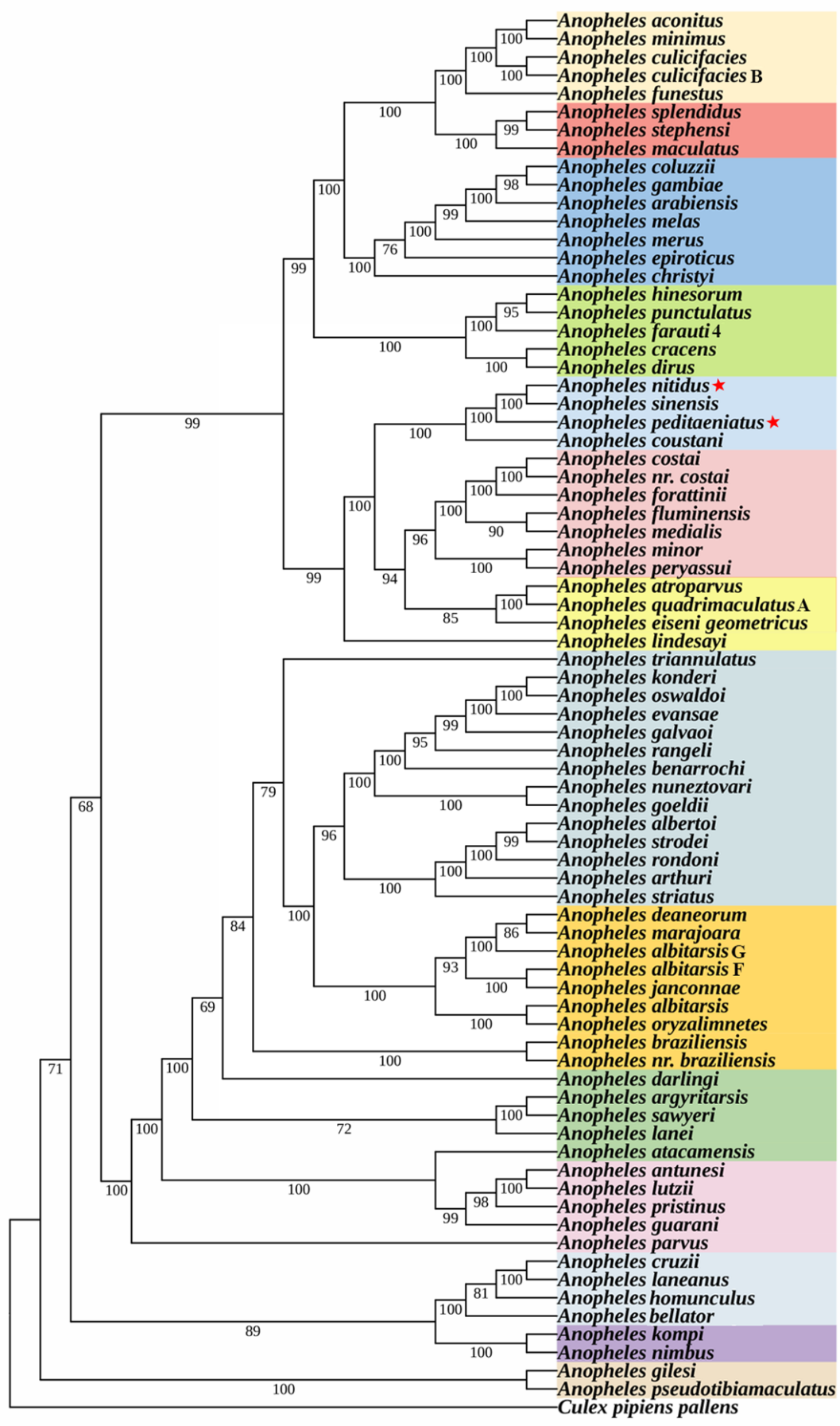

Myzomyia

Cellia

Pyretophorous

Neomyzomyia

Myzorhynchus

Laticorn

Arribalzagia

Laticorn

Anopheles

Anopheles

Angusticorn

Oswaldoi Albimanus

Albitarsis

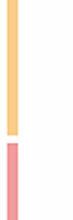

Argyritarsis
Argyritarsis
Myzorhynchella

Nyssorhynchus

\section{Kerteszia}

Stethomyia

Outgroup

Figure 6

Phylogenetic relationships of $76 \mathrm{mtgenomes}$ in the genus Anopheles. The phylogenetic tree was constructed based on nucleotide sequences of 13 protein-coding genes using Maximum Likelihood. The numbers at the nodes is bootstrap values. The mtgenomes of two species newly sequenced in this study are indicated by pentagrams. The GenBank accession numbers of the 76 mtgenome sequences are listed in Table 1.

\section{Supplementary Files}


This is a list of supplementary files associated with this preprint. Click to download.

- Additionalfile1TableS1.doc

- Additionalfile2Tables2.xls

- Additionalfile3FigureS1.doc

- Additionalfile4Figures2.doc

- Graphicalabstract.tif 